\title{
Activation of oxidative carbon metabolism by nutritional enrichment by photosynthesis and exogenous organic compounds in the red alga Cyanidioschyzon merolae: evidence for heterotrophic growth
}

Takashi Moriyama ${ }^{1,2^{*}}$, Natsumi Mori ${ }^{1,2}$ and Naoki Sato ${ }^{1,2}$

\section{${ }^{*}$ Correspondence:}

moripoly@bio.c.u-tokyo.ac.jp

2 JST, CREST, K's Gobancho

7 Gobancho, Chiyoda-ku,

Tokyo 102-0076, Japan

Full list of author information

is available at the end of the article

\begin{abstract}
Respiration is an important process in photosynthetic organisms, as it is in other organisms, for the supply of ATP and metabolites required for biosynthesis. Furthermore, individual enzymatic activity is subject to regulation by metabolic intermediates in glycolysis and the citric acid cycle. However, little is known about how glycolysis or catabolism are related to photosynthetic activity or accumulation of photosynthetic products. We previously developed a flat-plate culture apparatus assembled from materials commonly used for gel electrophoresis, which enables high-density culture of the unicellular red alga Cyanidioschyzon merolae. In this study, a stationary dense culture of $C$. merolae, when re-activated in this culture apparatus, exhibited an accumulation of photosynthetically produced starch. We demonstrated that respiratory activity increased during the culture period, while photosynthetic activity remained constant. Gene expression analysis revealed that the genes involved in cytosolic glycolysis and the citric acid cycle were selectively activated, compared to the genes for the oxidative pentose phosphate pathway and the Calvin-Benson cycle. Measurements of the respiratory rate after addition of various organic substances showed that $C$. merolae can utilize almost any exogenous organic compound as a respiratory substrate, although the effectiveness of each compound was dependent on the culture time in the flatplate culture, suggesting that glycolysis was rate-limiting to respiration, and its activity depended on the level of photosynthetic products within the cells. We also demonstrated that organic substances increased the rate of cell growth under dim light and, interestingly, C. merolae could grow heterotrophically in the presence of glycerol. Obligate photoautotrophy should be considered an ecological, rather than physiological, characteristic of C. merolae.
\end{abstract}

Keywords: Alga, Glycolysis, Heterotrophic growth, Obligate-photoautotrophic growth, Organic nutrition, Photosynthesis, Respiration

\section{Background}

Photosynthetic organisms consume oxygen through respiration and produce it through photosynthetic oxygen evolution. In plants, the respiratory rate is estimated to be $1 / 6$

\section{望 Springer}

(c) 2015 Moriyama et al. This article is distributed under the terms of the Creative Commons Attribution 4.0 International License (http://creativecommons.org/licenses/by/4.0/), which permits unrestricted use, distribution, and reproduction in any medium, provided you give appropriate credit to the original author(s) and the source, provide a link to the Creative Commons license, and indicate if changes were made. 
to $1 / 20$ of the photosynthetic rate (Radoglou and Teskey 1997). Respiration is the main source of cytosolic ATP, even in light-irradiated leaves (Krömer 1995), and also supplies metabolites required for biosynthesis, such as 2-oxoglutarate (2OG, Hoefnagel et al. 1998). Defects in a gene that encodes part of the respiratory chain lead to poor leaf growth and a decrease in the rate of photosynthesis (Vedel et al. 1999). Plant respiration is regulated by phosphoenolpyruvate (PEP)-induced inhibition of ATP-dependent phosphofructokinase (PFK) and inverse activation of PFK by inorganic phosphate (Plaxton 1996). In addition, an increase in NADH concentration represses the activity of dehydrogenases in the citric acid cycle (McIntosh and Oliver 1992). In the green alga Chlorella pyrenoidosa, the rate of respiration is positively correlated with growth rate and gradually decreases in darkness (Geider and Osborne 1989). Although regulation of the enzymatic reactions in glycolysis and the citric acid cycle has been observed, little is known about how respiratory activity relates to photosynthetic activity or to the accumulation of photosynthetic products.

The unicellular red alga Cyanidioschyzon merolae thrives in hot (up to $50{ }^{\circ} \mathrm{C}$ ) and acidic ( $\mathrm{pH}$ 1.5-2.5) springs, while maintaining an intracellular $\mathrm{pH}$ of 6.4 (Zenvirth et al. 1985). The cell structure of C. merolae is simple, consisting of one plastid and one mitochondrion per cell. The nuclear (Matsuzaki et al. 2004; Nozaki et al. 2007), mitochondrial (Ohta et al. 1998), and plastid (Ohta et al. 2003) DNA have been sequenced. The nuclear genome of C. merolae is remarkably compact in structure: its size is 16.5 Mbp; its predicted number of protein-coding genes is 4774 (Nozaki et al. 2007; Moriyama et al. 2014a), with low redundancy; and its number of intron-containing genes is 26. Transformation of C. merolae is easily achieved using the polyethylene glycol (PEG) method (Ohnuma et al. 2008), and subcellular localization of $3 \times$ hemagglutinin (HA)tagged and GFP-fused proteins in transformants has been reported (Ohnuma et al. 2008; Watanabe et al. 2011; Moriyama et al. 2014b). Comprehensive subcellular localization analysis has shown that the subcellular distribution of carbon metabolic pathways in C. merolae is essentially identical to that in Arabidopsis thaliana; namely, glycolysis is localized to the cytosol and plastid, while the Calvin-Benson and citric acid cycles exist in the plastid and mitochondrion (Moriyama et al. 2014a). However, C. merolae lacks transaldolase, an enzyme of the oxidative pentose phosphate pathway.

Cyanidioschyzon merolae belongs to the order Cyanidiales in the phylum Rhodophyta. This order consists of two genera besides Cyanidioschyzon: Galdieria and Cyanidium. Galdieria sulphuraria (Gross and Schnarrenberger 1995) and Cyanidium caldarium (Rigano et al. 1977) both grow under heterotrophic conditions, whereas C. merolae is thought to be an obligate photoautotroph (Raven et al. 1990). Genomic analyses of genes related to carbon metabolism have suggested that C. merolae, like G. sulphuraria, harbors metabolic pathways for floridoside, trehalose, storage glucans, and matrix polysaccharides (Barbier et al. 2005). For storage glucans, C. merolae contains semiamylopectin-type glucans without amylose (Hirabaru et al. 2010). C. merolae is predicted to contain a minimal set of metabolic transporters, such as those for triose phosphate, but no aquaporin-type glycerol permease for uptake of glycerol from the environment, or plastidic dicarboxylate translocators, which are required for nitrogen assimilation and for photorespiration and which are conserved in green plants and algae (Barbier et al. 2005; Tyra et al. 2007). 
In this study, we reexamined the utilization efficiency of exogenous organic substances as a carbon source in C. merolae, which previously was thought to be an obligate photoautotroph and to not have any transporters for uptake of exogenous compounds. Our results indicate that $C$. merolae efficiently utilizes various exogenous substrates for respiration and growth, and C. merolae can heterotrophically grow in glycerol-containing medium, but not in medium containing glucose, succinic acid, or lactic acid. We also examined the regulation of respiration by exogenously added organic compounds in cells as a function of flat-plate culture time. Our results suggest that the glycolytic pathway is rate-limiting to respiration, and the activity of the pathway varies dramatically depending on the amount of photosynthetic products.

\section{Results}

\section{Physiological changes in C. merolae cells grown in flat-plate culture}

Previously, we reported a culture method using a flat-plate culture apparatus (Fig. 1a), which alleviates the restriction of light availability caused by the self-shading of cells in a culture of high cell density (Moriyama et al. 2014b). In this study, the physiological characteristics of the cells grown in the apparatus were first determined. Subcultured cells in the stationary phase were concentrated to a culture turbidity $\left(\mathrm{OD}_{750}\right)$ of 10 , and then were cultured in a conical flask with rotary shaking overnight to exhaust the intracellular nutrients, such as floridean starch. Then the cells were transferred to the flat-plate culture apparatus and cultured under high light $\left(250 \mu \mathrm{mol}\right.$ photons $\left.\mathrm{m}^{-2} \mathrm{~s}^{-1}\right)$ with aeration by air containing $1 \% \mathrm{CO}_{2}$ at $40{ }^{\circ} \mathrm{C}$ for $6 \mathrm{~h}$.

The number of cells remained constant in the culture, although the $\mathrm{OD}_{750}$ increased exponentially (Fig. 1b), suggesting that the average cell size or intracellular density increased without cell division in the culture. The thickness of the apparatus was $2 \mathrm{~mm}$, allowing the transmission of 20 and $10 \%$, respectively, of the incident light from two krypton bulbs $\left(250 \mu \mathrm{mol}\right.$ photons $\left.\mathrm{m}^{-2} \mathrm{~s}^{-1}\right)$ through the culture apparatus filled with $C$. merolae culture at $0 \mathrm{~h}\left(\mathrm{OD}_{750}=10\right)$ and $6 \mathrm{~h}\left(\mathrm{OD}_{750}=18\right)$. The turbidity was measured at a distance from the cuvette, whereas the light transmission was measured just behind the plate; therefore, the plate transmittance and the turbidity are not related according to the Lambert-Beer Law. The photosynthetic rate, determined as the rate of oxygen evolution, was slightly increased at $1 \mathrm{~h}$ and then gradually decreased to the initial level seen at the beginning of the culture (Fig. 1c). On the other hand, the respiratory rate, determined as the rate of oxygen consumption, increased linearly in proportion to the culture time (Fig. 1c). The ratio of photosynthetic rate to respiratory rate was 29, 7, 4, and 2 at 0 , 1,3 , and $6 \mathrm{~h}$, respectively. The starch content of the cells was scarcely detectable at $0 \mathrm{~h}$ and then dramatically increased during the culture; thus, the cellular nutritional state changed from poor to enriched during the flat-plate culture. In contrast, the protein content increased only slightly (Fig. 1d), therefore, respiratory and photosynthetic rates were normalized by the protein content in this study.

Figure 1e shows bright field images of the cells in the flat-plate culture. The cells, which began as slender $(0 \mathrm{~h})$, became more rounded as the culture proceeded $(1-6 \mathrm{~h})$. To further characterize this change in cell shape, each cell was subdivided into a plastid compartment and an extra-plastid compartment containing the cytosol, nucleus, mitochondrion, and other organelles (Fig. 1f), and the areas and the longitudinal/transverse diameters 

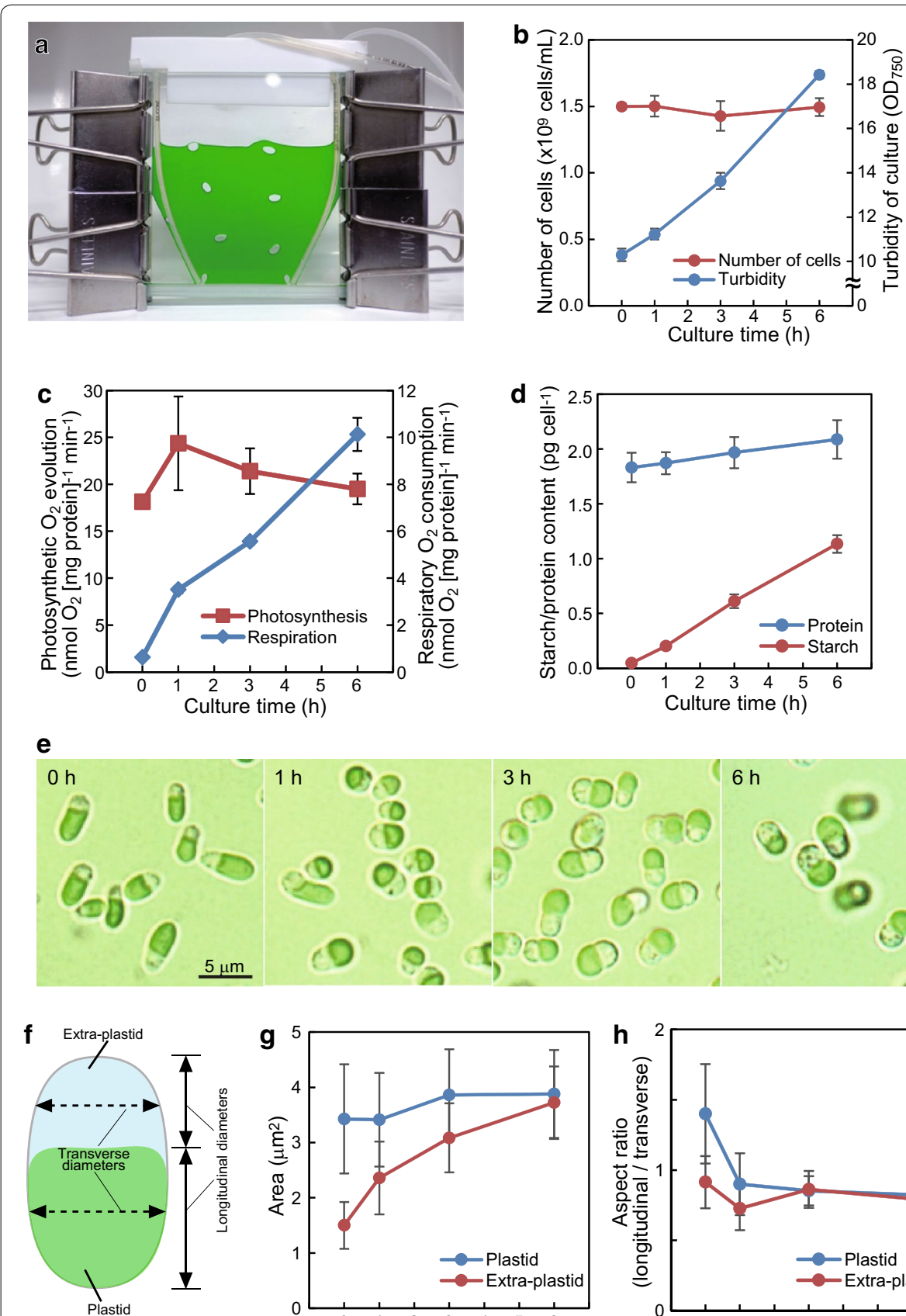

$(6 \mathrm{~h}$
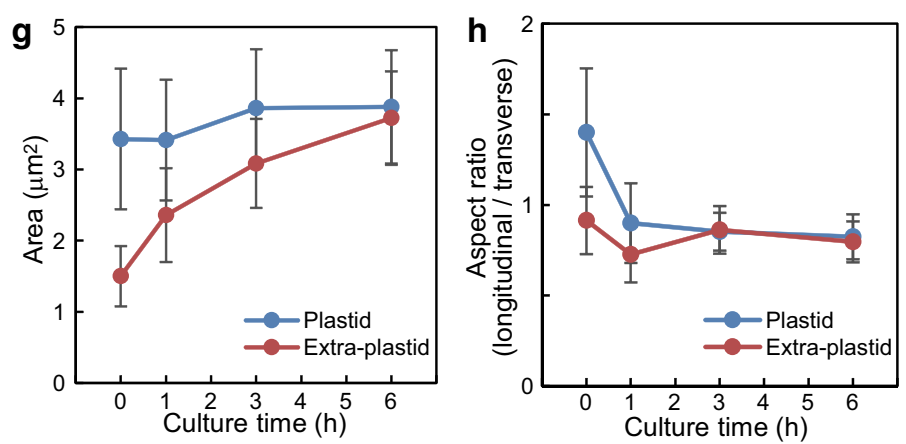

Fig. 1 Physiological changes in C. merolae cells grown in the flat-plate culture apparatus. a A picture of the flat-plate culture. Changes in number of cells and turbidity of culture $(\mathbf{b})$, photosynthetic and respiratory rates (c), and contents of starch and protein (d) during the flat-plate culture. Each value is an average \pm standard deviation of triplicates (b-d). e Normarski differential interference contrast images of cells at 0, 1, 3, and $6 \mathrm{~h}$ in the flat-plate culture. $\mathbf{f}$ A schematic image of $C$. merolae cell indicating plastid and extra-plastid compartments. Measured transverse and longitudinal diameters of each compartment are also shown. Changes in area $(\mathbf{g})$ and aspect ratio $(\mathbf{h})$ of plastid and extra-plastid. Each value is an average \pm standard deviation of measurement for 30 cells ( $\mathbf{g}, \mathbf{h})$ 
were measured (Fig. 1g, h, Additional file 1: Figure S1). The areas of the plastids remained constant, although the aspect ratios changed. Namely, the plastid shape was longitudinally long in the poor nutrient state ( $0 \mathrm{~h}$ of culture), whereas the shape became transversely long at 1-6 h of culture. In contrast, the area of the extra-plastid space increased during the culture period, while the aspect ratios were constant, with a transversely long shape.

\section{Subcellular localization of enzymes related to glycerol and lactate metabolism in C. merolae}

Subcellular localization analysis of the enzymes related to carbon metabolism gives information about the cellular metabolic flow within the cell. Previously, we reported on the localization of principal enzymes of the central carbon metabolic pathways (Moriyama et al. 2014a). In this study, we determined the localization of enzymes related to glycerol and lactate metabolism using GFP (Fig. 2a).

Glycerol is reversibly converted into glycerol 3-phosphate (G3P) by glycerol kinase (GK), and then reversibly converted into dihydroxyacetone phosphate (DHAP) by
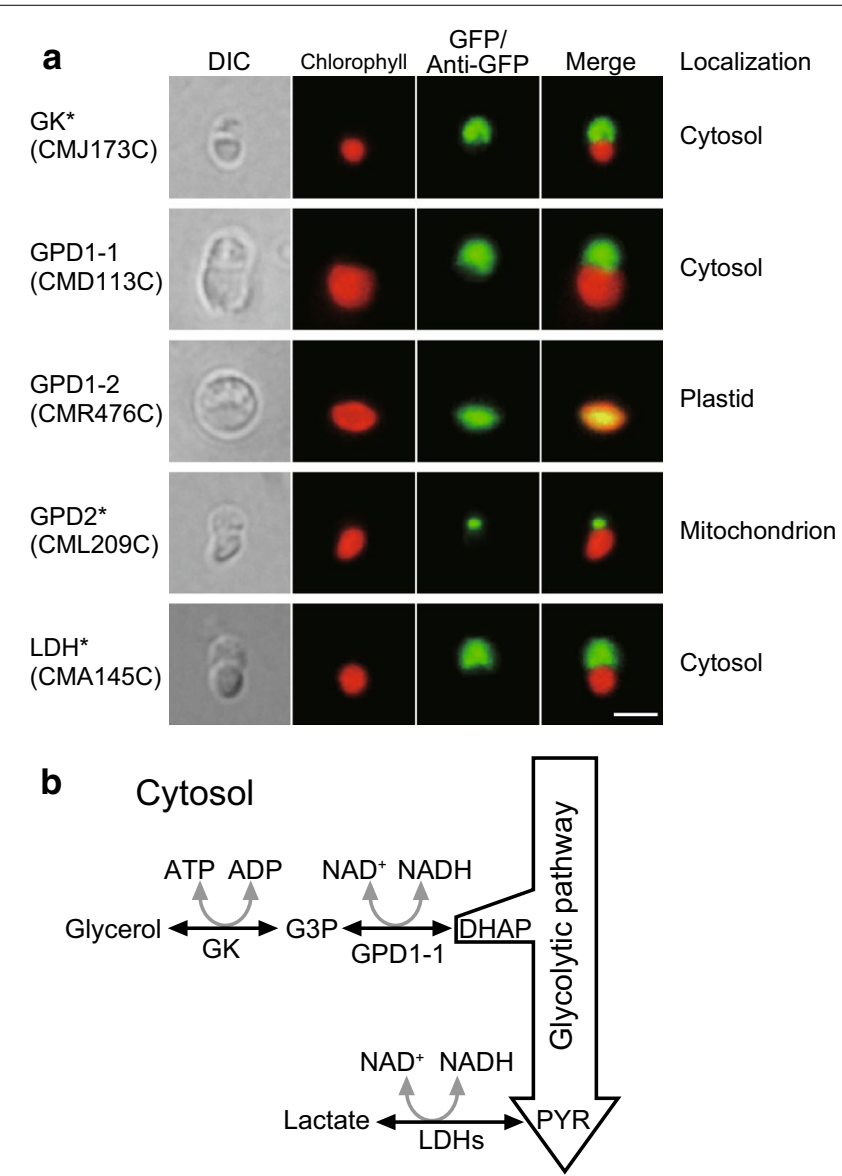

Fig. 2 Subcellular localization of GFP-fusion proteins related to glycerol and lactate metabolism in C. merolae cells. a Fluorescence microscopic images of transiently transformed C. merolae cells. Asterisks show images observed by immunofluorescence with anti-GFP antibody. Scale bar indicates $2 \mu \mathrm{m}$. DIC Normarski differential interference contrast images, Chlorophyll chlorophyll autofluorescence, Merge merged images of green fluorescence and chlorophyll autofluorescence. b Metabolic pathways for glycerol and lactate in C. merolae. DHAP dihydroxyacetone phosphate, G3P glycerol 3-phosphate, PYR pyruvate 
glycerol 3-phosphate dehydrogenase (GPD). Then DHAP is metabolized in the glycolytic pathway. The C. merolae genome encodes one GK (CM)173C [protein ID in Cyanidioschyzon merolae genome project, http://merolae.biol.s.u-tokyo.ac.jp/]), two $\mathrm{NAD}^{+}$-dependent GPDs (GPD1-1, CMD113C; GPD1-2, CMR476C), and one FADdependent GPD (GPD2, CML209C). GFP analysis showed cytosolic localization of GK and GPD1-1. GPD1-2 and GPD2, however, were localized to the plastid and mitochondrion, respectively.

Lactate dehydrogenase $(\mathrm{LDH})$ catalyzes the $\mathrm{NAD}^{+}$-dependent reversible conversion of pyruvate to lactate. C. merolae has five LDHs (CMA145C, CMC188C, CMI306C, $\mathrm{CMJ002}$, and CMK006C), which have high sequence similarity with one another. As a representative, we cloned CMA145C into a PCEG vector and found that the LDH was localized to the cytosol. The other LDHs are presumed to also be localized to the cytosol. Together, these results suggest that glycerol and lactate are metabolized, with production of NADH, in the cytosol in C. merolae (Fig. 2b). The reducing power of cytosolic $\mathrm{NADH}$ is presumably transferred to mitochondria via the G3P shuttle, which consists of cytosolic GPD1 and mitochondrial GPD2, as it is in A. thaliana (Shen et al. 2003).

\section{Gene expression analysis of central carbon metabolism in C. merolae cells grown in flat-plate culture}

The transcript levels of genes related to central carbon metabolism, including the glycolytic and oxidative pentose phosphate pathways, as well as the Calvin-Benson and citric acid cycles, were measured using quantitative RT-PCR at $0,1,3$, and $6 \mathrm{~h}$ in the flat-plate culture (Additional file 1: Figure S2). In the assay, 12 genes showed constant transcript levels (Additional file 1: Figure S2a). The transcript levels of the other 70 genes increased 2 - to 110 -fold at $1 \mathrm{~h}$ and then remained constant to $6 \mathrm{~h}$ (Additional file 1: Figure S2b-f). Figure 3 shows a result of expression mapping of the carbon metabolic pathways, based on their subcellular localizations determined previously (Moriyama et al. 2014a) and in this study (Fig. 2). The extent of the increases in gene expression, compared to the level at $0 \mathrm{~h}$, is color-coded. Four of the enzymes [6-phosphogluconolactonase (PGL), triosephosphate isomerase (TPI), phosphoglycerate kinase (PGK), and ribose-5-phosphate isomerase (RPI)] are localized to both the cytosol and plastid.

The transcript levels of many of the cytosolic glycolytic genes increased dramatically during the culture. In particular, the transcript levels of the genes for PPi-dependent phosphofructokinase (PFP), glyceraldehyde 3-phosphate dehydrogenase (GAPC-2), phosphoglycerate mutase (PGAM), and pyruvate kinase (PK-2), increased 37-, 45-, 62-, and 35-fold, respectively (Additional file 1: Figure S2f). The increase in expression of the plastid glycolytic genes was relatively less than that of the cytosolic glycolytic genes. In the plastid glycolytic genes, the transcript levels of $P K-1$ and $P D H-E 2-3$, the protein products of which are related to synthesis of acetyl-CoA used in fatty acid synthesis, increased dramatically. The complete oxidative pentose phosphate pathway is localized to the plastid, but a partial pathway is also present in the cytosol. The variation in transcript levels of these genes was small. The transcript levels of the Calvin-Benson cycle genes, some of which are shared by the oxidative pentose phosphate pathway, increased relatively little. Among the citric acid cycle genes, the transcript levels of $M D H-1, C S-4$, and IDH1 increased 22-, 20-, and 110-fold, respectively. The C. merolae genome encodes 


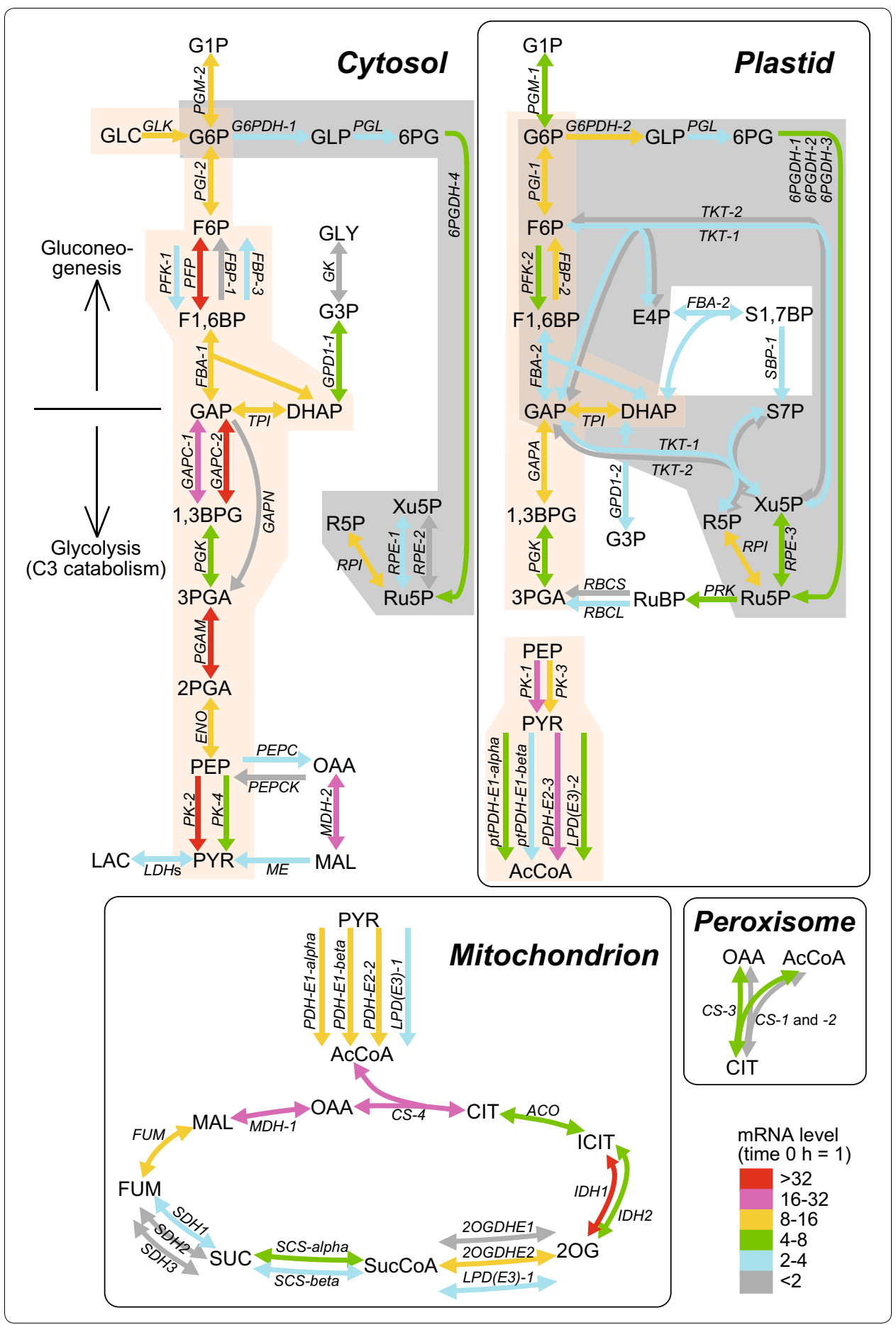

three peroxisomal citrate synthase genes, CS-1, CS-2, and CS-3, which are believed to be involved in the metabolism of acetyl-CoA produced by $\beta$-oxidation of fatty acids (Moriyama et al. 2014a); increases in the transcript levels of these peroxisomal CS genes were less than that of mitochondrial CS-4. These results suggest that the regulation of expression of at least some of the cytosolic glycolytic and citric acid cycle genes, which were severely suppressed in the poor nutrient state $(0 \mathrm{~h}$ of culture), was related 
(See figure on previous page.)

Fig. 3 Changes in gene expression in flat-plate culture. Transcript levels of genes related to glycolytic and oxidative pentose phosphate pathways, and Calvin-Benson and citric acid cycles were measured by quantitative RT-PCR. The peak of gene expressions during $0-6 \mathrm{~h}$ is color-coded. Explanatory color chart is shown at the lower right corner of this figure. Transcript level of SDH4 (succinate dehydrogenase hydrophobic subunit) was not determined because primer pair could not be designed by Primer Express software (Applied Biosystems) for crucially short and AT-rich sequence of $\mathrm{SDH} 4$ gene. Each gene name is shown on the arrows corresponding to enzymatic reaction. Orange and gray backgrounds show glycolytic and oxidative pentose phosphate pathways, respectively. Abbreviations of intermediates: 1,3BPG, 1,3-bisphoglycerate; 2OG, 2-oxoglutarate; 2PGA, 2-phosphoglycerate; 3PGA, 3-phosphoglycerate; 6PG, 6-phosphogluconate; AcCoA, acetyl-CoA; CIT, citrate; DHAP, dihydroxyacetone phosphate; E4P, erythrose 4-phosphate; F1,6BP, fructose 1,6-bisphosphate; F6P, fructose 6-phosphate; FUM, fumarate; G1P, Glucose 1-phosphate; G6P, glucose 6-phosphate; GAP, glyceraldehyde 3-phosphate; GLC, glucose; GLP, glucono 1,5-lactone 6-phosphate; ICIT, isocitrate; MAL, malate; OAA, oxaloacetate; PEP, phosphoenolpyruvate; PYR, pyruvate; R5P, ribose 5-phosphate; Ru5P, ribulose 5-phosphate; RuBP, ribulose 1,5-bisphosphate; S1,7BP, sedoheptulose 1,7-bisphosphate; S7P, sedoheptulose 7-phosphate; SUC, succinate; SucCoA, succinyl-CoA; Xu5P, xylulose 5-phosphate. Function of gene product: 2OGDH, 2-oxoglutarate dehydrogenase; 6PGDH, 6-phosphogluconate dehydrogenase; ACO, aconitase; $C S$, citrate synthase; $E N O$, enolase; $F B A$, fructose 1,6-bisphosphate aldolase; $F B P$, fructose 1,6-bisphosphatase; FUM, fumarase; G6PDH, glucose 6-phosphate dehydrogenase; GAPA, GAP dehydrogenase (NADP ${ }^{+}$ dependent, phosphorylating); GAPC, GAP dehydrogenase (NAD+ dependent, phosphorylating); GAPN, GAP dehydrogenase ( $\mathrm{NADP}^{+}$dependent, non-phosphorylating); $G L K$, glucokinase; ICDH, isocitrate dehydrogenase $\left(\mathrm{NADP}^{+}\right.$dependent); IDH, isocitrate dehydrogenase (NAD+ dependent); $L P D(E 3)$, pyruvate dehydrogenase E3/dihydrolipoamide dehydrogenase; $M D H$, malate dehydrogenase; $M E$, malic enzyme (NADP ${ }^{+}$dependent); $P D H$, pyruvate dehydrogenase; $P E P C$, phosphoenolpyruvate carboxylase; $P E P C K$, phosphoenolpyruvate carboxykinase; PFK, phosphofructokinase (ATP dependent); PFP, phosphofructokinase (PPi dependent); PGAM, phosphoglycerate mutase; $P G I$, phosphoglucose isomerase; $P G K$, phosphoglycerate kinase; $P G L$, 6-phosphogluconolactonase; $P G M$, phosphoglucomutase; $P K$, pyruvate kinase; $P R K$, phosphoribulokinase; $R B C L$, ribulose bisphosphate carboxylase large subunit; $R B C S$, ribulose bisphosphate carboxylase small subunit; $R P E$, ribulose 5-phosphate 3-epimerase; RPI, ribose 5-phosphate isomerase; SBP, sedoheptulose 1,7-bisphosphatase; SCS, succinyl-CoA synthetase; $S D H 1$, succinate dehydrogenase (Complex II) flavoprotein subunit; $S D H 2$, succinate dehydrogenase iron-sulfur protein; SDH3, succinate dehydrogenase cytochrome B560 subunit; TKT, transketolase; TPI, triosephosphate isomerase

to the regulation of the respiratory rate, whereas the genes of photosynthetic proteins remained at a constant level of expression in C. merolae cells, regardless of the amount of photosynthetic products, to maintain a constant rate of photosynthesis.

\section{Effects of exogenous organic compounds on the respiratory rate in nutrient-deficient cells}

To evaluate the physiological effects of exogenous organic compounds in C. merolae cells, we measured the respiratory rate in cells grown in a shaken culture with high cell density $\left(\mathrm{OD}_{750}=10\right)$, corresponding to $\mathrm{t}=0$ in the flat-plate culture. Then, changes in the respiratory rate as a function of substrate concentration were evaluated for glycerol, sucrose, glucose, sorbitol, and mannitol (Fig. 4a). Sucrose might be partially hydrolyzed to glucose and fructose in $2 \times$ Allen's medium at low $\mathrm{pH}$ ( $\mathrm{pH}$ 2.5). Each of the added substrates increased the respiratory rate, with glycerol having the greatest effect. The respiratory rate plateaued at $200 \mathrm{mM}$ sugar for sucrose, glucose, sorbitol, and mannitol, and at $600 \mathrm{mM}$ glycerol, and then decreased with higher concentrations.

Based on these results, various substrates, including sugars, alcohols, carboxylic acids, and amino acids, were added to the cells at $0 \mathrm{~h}$ in the flat-plate culture at a concentration of $200 \mathrm{mM}$ (Fig. 4b). Due to the low solubility of leucine, aspartate, and glutamate, these amino acids were added at a concentration of $100 \mathrm{mM}$. Stock solutions of fumaric acid, succinic acid, and pantothenate were adjusted to $\mathrm{pH}$ 5.2, $\mathrm{pH} 4.5$, and $\mathrm{pH}$ 5.0, respectively, and solutions of the other carboxylic acids and amino acids were adjusted 

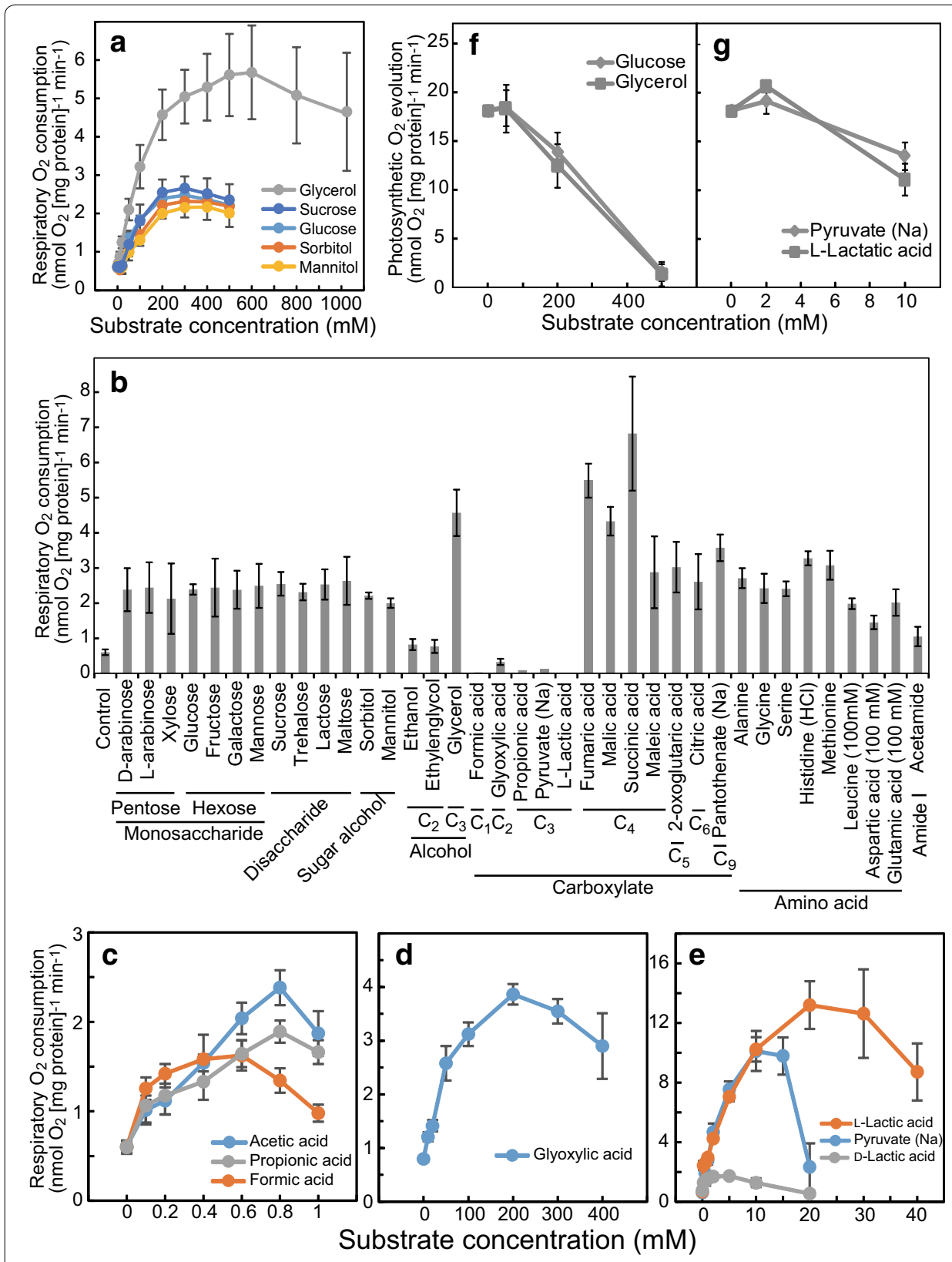

Fig. 4 Effects of exogenous organic substances on respiratory and photosynthetic rates in nutrient-deficient cells. Organic substrates were added to culture at $0 \mathrm{~h}$ in the flat-plate culture. a Respiratory oxygen consumption rate (respiratory rate) dependent on sugar concentration. b Respiratory rate with addition of organic substances at $200 \mathrm{mM}$. Leucine, aspartic acid, and glutamic acid were added to the culture at $100 \mathrm{mM}$ for their low aqueous solubility. Respiratory rate dependent on concentration of acetic acid, propionic acid, and formic acid (c), glyoxylic acid (d), and L-lactic acid, pyruvate, and D-lactic acid (e). Photosynthetic oxygen evolution rate dependent on concentration of glucose and glycerol (f) and pyruvate and L-lactic acid (g). Each value is an average \pm standard deviation of triplicates

to $\mathrm{pH}$ 2.5. Monosaccharides, disaccharides, sugar alcohols, carboxylic acids (maleic acid, 2-oxoglutaric acid, citric acid, and pantothenate), and amino acids increased the respiratory rate 3- to 6-fold, whereas ethanol, ethylene glycol, and acetamide increased the respiratory rate 2-fold. Glycerol and four-carbon-atom carboxylic acids (fumaric acid, malic 
acid, and succinic acid) increased the respiratory rate 7- to 11-fold. Carboxylic acids with a carbon number less than three proved toxic to $C$. merolae cells, which immediately turned yellow and died when the concentration of carboxylic acids was $200 \mathrm{mM}$.

To better characterize the effects of short-chain carboxylic acids on the respiratory rate, these substrates were added to the culture at low concentration (Fig. 4c-e). Upon addition of $1 \mathrm{mM}$ acetic acid, propionic acid, or formic acid, C. merolae cells survived, and the respiratory rate increased 3- to 4-fold (Fig. 4c). Glyoxylic acid could be added to the culture up to $400 \mathrm{mM}$, and the respiratory rate increased 4-fold at a concentration of $200 \mathrm{mM}$. Figure 4b, d show the contrasting effects of $200 \mathrm{mM}$ glyoxylic acid on the respiratory rate, probably due to differences in the method of substrate addition. In the assay of Fig. 4b, glyoxylic acid was added to the culture to a final concentration of $200 \mathrm{mM}$ at once, whereas in Fig. 4d the glyoxylic acid was added step-wise to final concentrations of 10,20,50,100,200,300, and $400 \mathrm{mM}$, with 10 min intervals between additions. Thus, the cells appear to have acclimated to the glyoxylic acid in Fig. 4d. L-Lactic acid and pyruvate increased the respiratory rate 19- and 16-fold, respectively (Fig. 4e). D-Lactic acid had virtually no effect on the respiratory rate (Fig. 4e), suggesting that L-lactic acid was specifically metabolized by lactate dehydrogenases in C. merolae.

Assuming that respiratory oxygen consumption behaves as a single enzyme-catalyzed reaction, we applied Michaelis-Menten kinetics to the substrate concentrationdependent respiratory rates in the results shown in Fig. 4a, c-e (Table 1). Because cells were assumed to contain internal substrates for respiration, a parameter was added to account for the concentration of intracellular substrate $\left(S_{\text {in }}\right)$; thus, the modified Michaelis-Menten equation was $v=V_{\max } \cdot\left([S]+\left[S_{\text {in }}\right]\right) / K_{\mathrm{s}}+\left([S]+\left[S_{\text {in }}\right]\right) . K_{\mathrm{s}}$ indicates the apparent $K_{\mathrm{m}}$; that is, the substrate concentration $(S)$ at which the rate of respiration was half maximal (i.e., $\left.v=1 / 2 V_{\max }\right) . V_{\max }$ values were high for L-lactic acid, pyruvate, and glycerol. The $K_{\mathrm{s}}$ values for carboxylic acids with a carbon number less than three were smaller than those for sugars and glycerol. Taken together, we interpret these results

Table 1 Kinetics for exogenous substrates on respiratory rate in nutrient-deficient cells

\begin{tabular}{lcccc}
\hline Substrates & $\boldsymbol{V}_{\mathbf{m a x}}$ & $\boldsymbol{K}_{\mathbf{s}}(\mathbf{m} \mathbf{M})$ & $\boldsymbol{S}_{\mathbf{i n}}(\mathbf{m} \mathbf{M})$ & $\boldsymbol{R}^{\mathbf{2}}$ \\
\hline L-Lactic acid & $16.3 \pm 1.2$ & $6.7 \pm 1.7$ & $0.6 \pm 0.3$ & 0.94 \\
Pyruvate (Na) & $12.8 \pm 0.9$ & $3.7 \pm 0.8$ & $0.1 \pm 0.1$ & 0.96 \\
Glycerol & $7.1 \pm 0.6$ & $132 \pm 34$ & $10 \pm 5$ & 0.94 \\
Glyoxylic acid & $4.4 \pm 0.2$ & $47 \pm 10$ & $21 \pm 10$ & 0.95 \\
Sucrose & $4.3 \pm 0.8$ & $174 \pm 82$ & $41 \pm 16$ & 0.91 \\
Mannitol & $4.2 \pm 1.1$ & $296 \pm 164$ & $29 \pm 5$ & 0.93 \\
Sorbitol & $4.1 \pm 0.4$ & $231 \pm 51$ & $17 \pm 4$ & 0.97 \\
Glucose & $3.4 \pm 0.2$ & $105 \pm 20$ & $0.10 \pm 0.06$ & 0.96 \\
Acetic acid & $3.0 \pm 0.6$ & $0.43 \pm 0.25$ & $0.01 \pm 0.05$ & 0.84 \\
Propionic acid & $2.2 \pm 0.2$ & $0.24 \pm 0.12$ & $0.03 \pm 0.01$ & 0.84 \\
Formic acid & $1.8 \pm 0.1$ & $0.05 \pm 0.03$ & $0.1 \pm 0.1$ & 0.88 \\
D-Lactic acid & $1.8 \pm 0.1$ & $0.13 \pm 0.07$ & 0.76 \\
\hline
\end{tabular}

Kinetic parameters were calculated by fitting to the modified Michaelis-Menten equation:

$v=V_{\max }\left([S]+\left[S_{\text {in }}\right]\right) / K_{\mathrm{s}}+\left([S]+\left[S_{\text {in }}\right]\right) . V_{\max }\left(\mathrm{nmol} \mathrm{O}{ }_{2}[\mathrm{mg} \text { protein }]^{-1} \mathrm{~min}^{-1}\right)$ indicates maximal velocity of respiration. $K_{s}$ indicates the substrate concentration which corresponds to the half of $V_{\max }$. $S$ means the concentration of exogenous substrate. $S_{\text {in }}$ means hypothetical concentration of intracellular substrate. $R^{2}$ indicates coefficient of determination. Substrates are shown in descending order for the value of $V_{\text {max }}$. Each value is an average \pm standard deviation of triplicates 
as follows: sugars, which are catabolized in the early steps of glycolysis, increased the respiratory rate approximately 4 -fold; glycerol, which is catabolized in a middle step of glycolysis, increased the rate 9-fold; pyruvate and L-lactic acid, both end products of glycolysis, increased the respiratory rate 16- or 19-fold; and fumaric acid, malic acid, and succinic acid, which are metabolized in the citric acid cycle, increased the respiratory rate 7 - to 11-fold. These observations suggest that the further downstream the organic substance is catabolized in the carbon metabolic pathway, the greater its effect on the respiratory rate.

Next, we examined the effects of glucose, glycerol, pyruvate, and L-lactic acid on photosynthetic oxygen evolution (Fig. 4f, g). The photosynthetic rate was not affected by $50 \mathrm{mM}$ glucose or glycerol (Fig. 4f), but decreased when these substrates were present at a concentration greater than $200 \mathrm{mM}$. The photosynthetic rate increased slightly in the presence of $2 \mathrm{mM}$ pyruvate or L-lactic acid, but decreased when these carboxylic acids were present at a concentration of $10 \mathrm{mM}$ (Fig. 4g). These results indicate that these organic substances have different effects on photosynthesis than on respiration.

\section{Effects of exogenous organic substances on respiration in C. merolae cells at different flat-plate culture times}

To examine the effects of exogenous compounds on respiration in C. merolae cells with different levels of starch accumulation, glucose, glycerol, pyruvate, and L-lactic acid were added to cells grown in the flat-plate culture at $0,1,3$, and $6 \mathrm{~h}$, and the respiratory rates were measured (Fig. 5a). In the kinetics assays (Table 1), we attempted, but were unable, to fit the large respiratory rates at 1,3 , and $6 \mathrm{~h}$ of flat-plate culture in the absence of added substrates to the modified Michaelis-Menten equation.

In the presence of glucose, the respiratory rate of nutrient-deficient cells (culture time of $0 \mathrm{~h}$ ) continued to increase up to a glucose concentration of $200 \mathrm{mM}$, whereas in cells cultured for 1 or $3 \mathrm{~h}$, the respiratory rates plateaued at a glucose concentration of $50 \mathrm{mM}$. Similar results were observed for glycerol. In cells cultured for $6 \mathrm{~h}$, the respiratory rate was unaltered by even high concentrations of glucose, whereas a slight increase was observed upon addition of exogenous glycerol. In addition, the maximum respiratory rate in the presence of glucose varied, depending on the culture time. In contrast with the effects of glucose and glycerol, the effects of pyruvate and L-lactic acid were similar among the cells at $0,1,3$, and $6 \mathrm{~h}$ of culture, but the optimum concentrations of these carboxylic acids were lower at later time points, at which the respiratory rate was higher. In addition, pyruvate and L-lactic acid increased the respiratory rate in cells cultured for $6 \mathrm{~h}$, and the maximum respiratory rates were similar at all culture times. Judging from the differences observed between the effects of the four exogenous substrates on the respiratory rates at $6 \mathrm{~h}$ of culture, there seem to be at least two rate-limiting steps in glycolysis, as measured by respiratory activity; namely, one between glucose 6-phosphate (G6P) to glyceraldehyde 3-phosphate (GAP), and one between GAP to pyruvate.

Figure $5 \mathrm{~b}$ shows plots of the maximum respiratory rate upon addition of four substances at different times of flat-plate culture. The plots can be interpreted as reflecting changes in the maximum activities of various portions of the carbon metabolic pathways. For example, the assay with exogenous glucose presumably measures the activity of the glycolytic pathway from G6P to GAP, while the assay with exogenous glycerol 

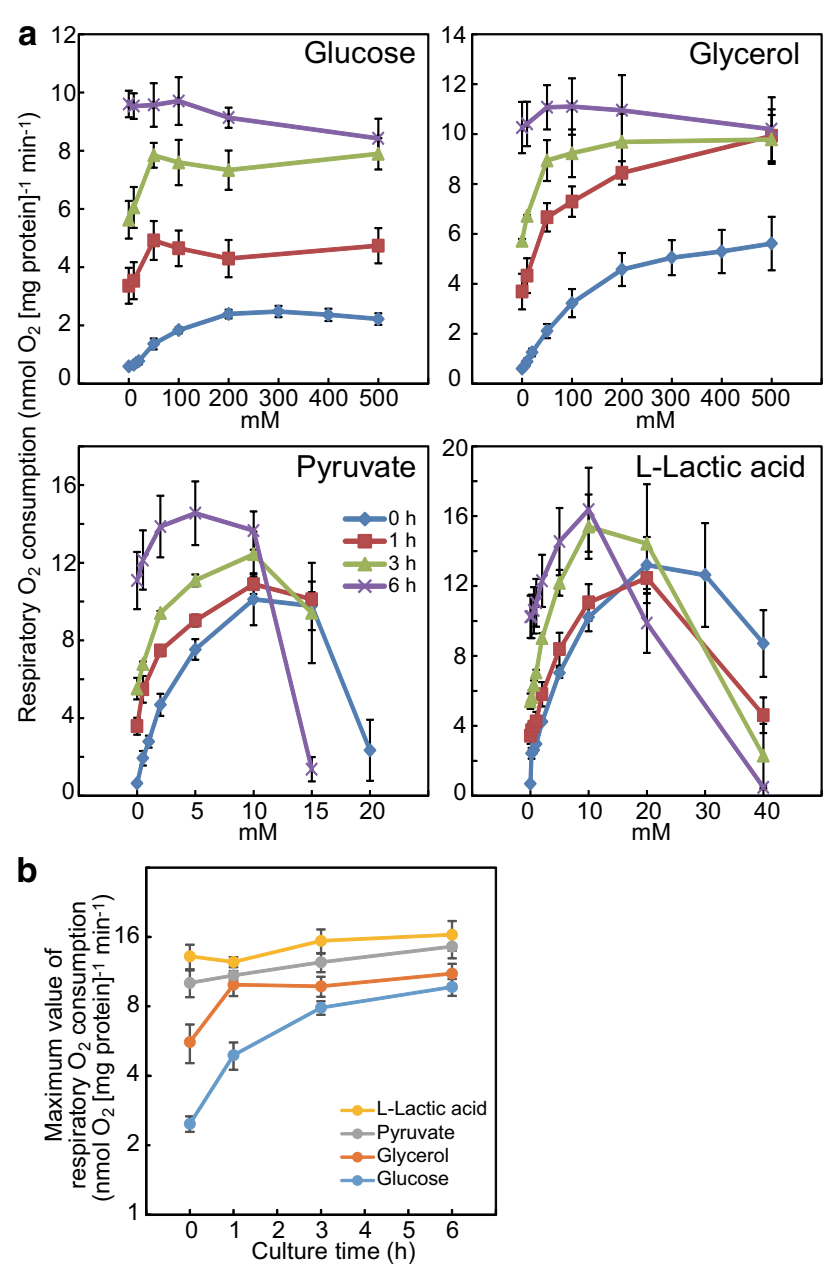

Fig. 5 Effects of organic substances on respiratory rate in C. merolae cells at different flat-plate culture times. a Glucose, glycerol, pyruvate, and L-lactic acid were added to culture at 0 (blue), 1 (red), 3 (light green), and $6 \mathrm{~h}$ (purple) in the flat-plate culture, and respiratory rate was measured. Results at $0 \mathrm{~h}$ are adopted from the results of Fig. 4 in each substance. Each value is an average \pm standard deviation of triplicates. $\mathbf{b}$ From the results of $(\mathbf{a})$, maximum values of respiratory rates at different culture times are plotted. Vertical scale is indicated as logarithmic scale

measures the activity from GAP to pyruvate, and the assay with exogenous pyruvate and L-lactic acid measures the activity of the downstream citric acid cycle. Interpreted from this viewpoint, the activity of the first half of glycolysis (G6P to GAP) increased dramatically during the flat-plate culture, while the activity of the latter half of glycolysis (GAP to pyruvate) reached a maximum at $1 \mathrm{~h}$ of flat-plate culture. In contrast, the increase in activity of the downstream citric acid cycle was relatively small.

\section{Effects of exogenous substrates on growth}

To examine whether the increase in respiratory rate induced by exogenous substrates was correlated with an increased rate of cell growth, glycerol, succinic acid ( $\mathrm{pH} 4.5$ ), and L-lactic acid ( $\mathrm{pH} 2.5$ ) were added to the culture to final concentrations of 50, 50, and $5 \mathrm{mM}$, respectively, and cell growth rates were determined (Table 2). At these 
Table 2 Mixotrophic growth rate in C. merolae

\begin{tabular}{|c|c|c|}
\hline \multirow[t]{2}{*}{ Added carbon source } & \multicolumn{2}{|l|}{ Doubling time (h) } \\
\hline & $\begin{array}{l}\text { Light: } 8 \mu \mathrm{mol} \text { photons } \mathrm{m}^{-2} \mathrm{~s}^{-1} \\
\text { Aeration: air }\end{array}$ & $\begin{array}{l}\text { Light: } 50 \mu \mathrm{mol} \text { photons } \mathrm{m}^{-2} \mathrm{~s}^{-1} \\
\text { Aeration: } 1 \% \mathrm{CO}_{2}\end{array}$ \\
\hline None & $35.6( \pm 2.1)$ & $12.7( \pm 0.5)$ \\
\hline 50 mM glycerol & $31.0( \pm 3.1)$ & $11.8( \pm 0.4)$ \\
\hline 50 mM succinic acid & $28.2( \pm 2.7)^{*}$ & $12.2( \pm 0.3)$ \\
\hline 5 mM L-lactic acid & $25.2( \pm 2.5)^{*}$ & $12.0( \pm 0.2)$ \\
\hline
\end{tabular}

Each value is an average \pm standard deviation of triplicates

${ }^{*} p<0.05$ in $t$ test (compared with control)

concentrations, these substrates effectively increased the respiratory rate but did not interfere with photosynthetic activity (Fig. 4f, g). The growth rates were measured under two conditions, one at low light intensity $\left(8 \mu \mathrm{mol}\right.$ photons $\left.\mathrm{m}^{-2} \mathrm{~s}^{-1}\right)$ while bubbling with ordinary air, and another at intermediate light intensity $\left(50 \mu \mathrm{mol}\right.$ photons $\left.\mathrm{m}^{-2} \mathrm{~s}^{-1}\right)$ while bubbling with air containing $1 \% \mathrm{CO}_{2}$. Under the former condition, relative to the control (without a carbon source), the growth rate increased and the doubling time was shortened by 4.6, 7.4, and 10.2 h with exogenous glycerol, succinic acid, and L-lactic acid, respectively. The order of effectiveness of the substrates on growth rate paralleled their effectiveness at increasing the respiratory rate; thus, L-lactic acid showed the highest effect on growth rate among the substrates examined under conditions of insufficient photosynthesis. The doubling time of the control was shorter under the second condition than under the first condition, and the growth rate was barely affected by the addition of exogenous substrates.

\section{Heterotrophic growth in C. merolae}

Cyanidioschyzon merolae was supplied with $200 \mathrm{mM}$ glucose, $200 \mathrm{mM}$ glycerol, $200 \mathrm{mM}$ succinic acid, or $5 \mathrm{mM}$ lactic acid and cultured in flasks shaken in the dark (Additional file 1: Figure S3). The C. merolae cells started to grow exponentially after 1 week in the presence of glycerol, although the doubling time was very long, approximately 1 week. In the presence of other substrates or no substrate (control), the turbidity of the culture continued to decrease over 4 weeks. In this assay, the cell cultures were exposed to room light at the sampling time for a short period of time. Next, the cells were cultured under complete darkness in a medium containing 50 or $200 \mathrm{mM}$ glycerol, and the turbidity was measured 3 weeks later, demonstrating that $C$. merolae could grow heterotrophically with $200 \mathrm{mM}$ glycerol (Fig. 6a, b). Under microscopic observation, the dark-grown cells in the presence of glycerol appeared to be normal in shape (Fig. 6c). On the other hand, the dark-grown cells without exogenous glycerol exhibited an abnormal shape with an extremely contracted cytosol and/or contraction between the cytosol and plastid (Fig. 6c).

\section{Discussion}

\section{Culture of $C$. merolae in the flat-plate culture apparatus}

We used the flat-plate culture system to measure respiratory rate in $C$. merolae cells with different levels of starch accumulation at high cell densities because effects of exogenous 


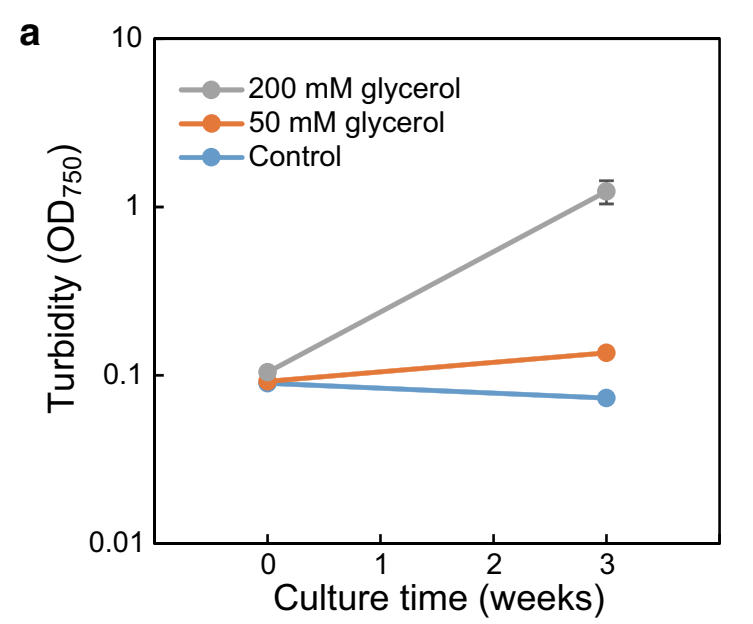

b

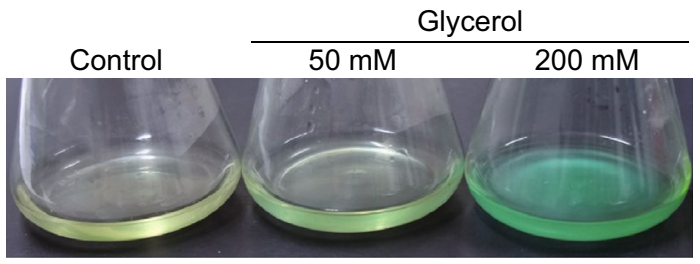

C

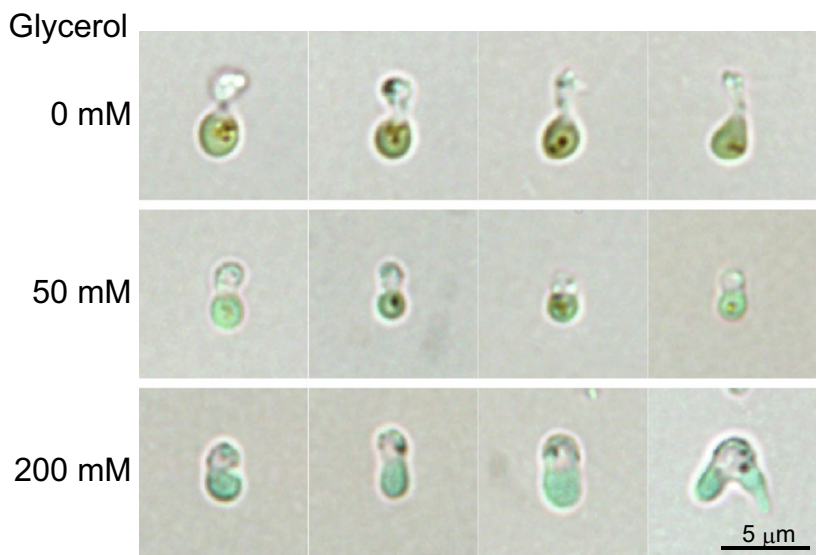

Fig. 6 Heterotrophic growth in C. merolae. C. merolae cells were grown with addition of 0, 50, and $200 \mathrm{mM}$ glycerol in rotary-shaken flasks under the darkness for 3 weeks. a Turbidity of dark-grown culture. Culture images in flasks (b) and microscopic images (c) after 3-week. In c, four cells are shown as representative. A dividing cell is shown on the extreme right at $200 \mathrm{mM}$ glycerol

substrates on respiratory rate were not measurable if the cells were in the logarithmic phase $\left(\mathrm{OD}_{750}<1\right)$. To obtain cells with a wide range of starch accumulation levels, the flat-plate culture was started using a shaken culture $\left(\mathrm{OD}_{750}=10\right)$. The cells at $0 \mathrm{~h}$ contained hardly any starch and did not undergo division, suggesting that the cell cycle was quiescent (i.e., in the G0 phase), and the cells reentered the G1 phase during the flatplate culture with high-light irradiation. In the green alga Chlamydomonas reinhardtii, the protein compromised hydrolysis of triacylglycerols 7 (CHT7), which contains a DNA binding domain and is localized to the nucleus, is related to quiescence with respect to cellular nutritional status (Tsai et al. 2014). In synchronous culture of C. merolae, cell 
division occurred at 10-12 $\mathrm{h}$ from the beginning of the light phase (Fujiwara et al. 2009; Moriyama et al. 2010), and therefore cells in the flat-plate culture will divide if the culture time is prolonged.

When physiological changes were measured in the flat-plate culture, the variance was small, indicating that individual cells were evenly irradiated by light. The flat-plate culture system consists of materials used commonly for gel electrophoresis, along with thin silicon tubes for aeration; thus, no special materials are required, and the culture system can be easily acquired by any laboratory. In addition, the system can be applied to other algae, as well as C. merolae.

\section{Utilization of exogenous organic substances by C. merolae}

As far as we examined, C. merolae could utilize almost any exogenous organic substance as a respiratory substrate (Fig. 4). In contrast, exogenous glucose and glycerol did not increase the photosynthetic rate, and excess substrate actually decreased this rate. The decrease in photosynthetic rate by addition of glucose and glycerol at high concentrations may have been caused by a rapid change in the osmotic pressure. Pyruvate and lactic acid slightly stimulated photosynthetic activity at low concentrations. Because photosynthetic rate is related to respiratory rate (Vedel et al. 1999), it is possible that in our study increased respiratory activity stimulated the photosynthetic activity. These results indicate that exogenous substrates were indeed imported into the cells. C. merolae encodes a single gene of sugar transporter (CMK066C). In A. thaliana, the monosaccharide/proton symporter AtSTPs, which have sequence similarity with CMK066C, transport various sugars, including glucose, fructose, galactose, mannose, xylose, and arabinose, into the cell (Truernit et al. 1999; Sherson et al. 2000). In C. merolae, monosaccharides were presumably taken up by the function of the sugar transporter, although the efficiency of uptake of exogenous sugars was low (i.e., the $K_{\mathrm{s}}$ values for sugars were large, Table 1). Exogenous glycerol dramatically increased the respiratory rate, although the $C$. merolae genome encodes no glycerol permease, unlike $G$. sulphuraria (Barbier et al. 2005). The cell membrane is highly permeable to glycerol, and glycerol permease may not be required for glycerol uptake in $C$. merolae, which lacks a cell wall (Oesterhelt et al. 2008). Short-chain carboxylic acids with a carbon number less than three are not significantly ionized in $2 \times$ Allen's medium because the acid dissociation constant $\left(\mathrm{p} K_{\mathrm{a}}\right)$ of these carboxylic acids is much greater than the $\mathrm{pH}$ value of the medium ( $\mathrm{pH}$ 2.5). Therefore, the short-chain carboxylic acids should easily diffuse into C. merolae cells, and indeed, the $K_{\mathrm{s}}$ values for these acids were much lower than those for the sugars (Table 1). Because of this high permeability, when short-chain carboxylic acids were added to the culture at a high concentration, it is plausible that the carboxylic acids rapidly entered the cells, and then, encountering a neutral $\mathrm{pH}$ (Zenvirth et al. 1985), ionized to release excess protons, resulting in cell death.

Under mixotrophic conditions, the efficiency with which exogenous substrates affected the growth rate in C. merolae was different than in the algae G. sulphuraria (Oesterhelt et al. 2007) and Chlamydomonas acidophila (Tittel et al. 2005), which can grow heterotrophically. In these algae, the growth rate effectively increased upon addition of carbon sources, even when the algae were irradiated with sufficient light intensity for photosynthesis. These results suggest that $C$. merolae cells with high photosynthetic 
activity can undergo cell division. We also demonstrated heterotrophic growth in $C$. merolae in the presence of glycerol (Fig. 6, Additional file 1: S3). Exogenous glycerol was presumably converted into DHAP or GAP in the cytosol. Because GAP is a product of photosynthesis and is transferred into the cytosol from the plastid under lighted conditions, a large amount of GAP derived from exogenous glycerol might mimic the state of cells actively performing photosynthesis. Accordingly, genes necessary for progression of the cell cycle might be transcribed in cells supplied with exogenous glycerol in darkness. The failure to observe heterotrophic growth with exogenous glucose, L-lactic acid, and succinic acid might also be explained by the level of GAP. Exogenous glucose would hardly be catabolized into GAP if the activities of enzymes in the first half of glycolysis, such as glucokinase, PFK, or fructose 1,6-bisphosphate aldolase, are suppressed in darkness. For L-lactic acid and succinic acid, these substrates are catabolized in the citric acid cycle, and metabolism of these substrates is not related to that of GAP. For verification of this hypothesis, transcriptome and metabolome analyses are needed.

Our results demonstrate that C. merolae can grow in darkness with $200 \mathrm{mM}$ glycerol. Similar results have been reported for the haptophyte Prymnesium parvum (Rahat and Jahn 1965) and marine cryptomonad Chroomonas salina (Antia et al. 1973); these algae can grow heterotrophically with $250 \mathrm{mM}$ exogenous glycerol. However, ecologically speaking, these algae are considered to be obligate photoautotrophs because very high concentrations of glycerol do not normally exist in their natural habitat (Droop 1974). Similarly, C. merolae may be considered an ecologically obligate photoautotroph.

\section{Regulation of respiration in C. merolae}

Figure 7 summarizes the results of this study. During flat-plate culture, the respiratory rate increased dramatically, while the photosynthetic rate was constant, irrespective of starch accumulation levels. The results of Fig. 5 suggest that glycolysis was ratelimiting to respiration. The respiratory process was subdivided into three pathways, namely, the pathway from G6P to GAP in glycolysis (G6P-GAP pathway), the pathway from GAP to pyruvate in glycolysis (GAP-PYR pathway), and the downstream pathway of the citric acid cycle. The GAP-PYR pathway was immediately activated in response to enrichment of the cellular nutritional status, which may reflect the necessity to rapidly catabolize GAP, which is a photosynthetic product and should be consumed as a

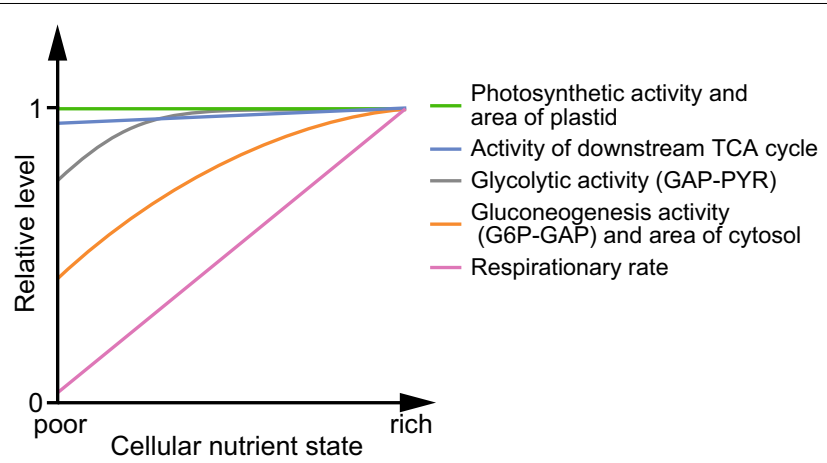

Fig. 7 Diagram showing the regulation of the activity of respiration and photosynthesis in C. merolae. Details of this diagram are explained in the last part in "Discussion" section 
respiratory substrate to maintain photosynthesis. The G6P-GAP pathway also increased, but the increase was milder than that in the GAP-PYR pathway and the increase continued throughout the $6 \mathrm{~h}$ of culture. The G6P-GAP pathway is used for both catabolism and anabolism of starch, which functions as storage for excess energy. The production of ATP and metabolites responsible for biosynthesis through the downstream GAP-PYR pathway might be prioritized over starch metabolism if the nutrient status of the cells is very low. The results of the gene expression analysis suggest that the regulation of the $P F P$ transcript level is related to the regulation of the G6P-GAP pathway, and the regulation of the transcript levels of GAPC, PGAM, and $P K$ are related to the regulation of the GAP-PYR pathway. In plants, the expression level of PFP (Groenewald and Botha 2007) and GAPC (Zaffagnini et al. 2013) is related to the regulation of the respiratory rate. In contrast to glycolytic activity, the activity of the downstream citric acid cycle was largely unaltered, although some citric acid cycle genes showed large changes in expression level during the flat-plate culture. Upon increase in the activity of these metabolic pathways, the respiratory rate increased dramatically during the flat-plate culture, indicating that the amount of respiratory substrate limits the respiratory rate and has an influence on the ratio of photosynthetic rate to respiratory rate.

We found that cell size and shape also changed during the flat-plate culture. Changes in the areas of the plastid and extra-plastid compartments reflect the photosynthetic and glycolytic (G6P-PYR) activities, respectively. Because starch is synthesized and accumulated in the cytosol in red algae, the increase in the area of the extra-plastid compartment appears to be due mainly to an increase in the accumulation of starch. Alternatively, the development of cytosolic glycolysis and/or mitochondrial TCA cycle/electron transfer system may contribute to the increase in the area of the extra-plastid space. Because $C$. merolae has no cell wall, the shape and size of the cell may be variable in response to cellular nutritional states.

\section{Conclusions}

Cyanidioschyzon merolae utilizes exogenous organic substances as substrates for respiration, the rate of which is mainly regulated by modulation of cytosolic glycolytic activity in response to the level of starch accumulation. This activity seems to metabolize the photosynthetic product GAP to maintain the rate of photosynthesis. Exogenous organic compounds indeed accelerate the growth of $C$. merolae under mixotrophic conditions. Furthermore, we demonstrated that $C$. merolae, which was thought to be an obligate photoautotroph, can heterotrophically grow in medium containing glycerol, but not other organic substances. The cellular state in which GAP is synthesized from exogenous glycerol may mimic the state of cells actively performing photosynthesis.

\section{Methods}

\section{Culture conditions of C. merolae}

Cyanidioschyzon merolae strain 10D (Toda et al. 1998) was grown in $100 \mathrm{~mL} 2 \times$ Allen's medium (pH 2.5; Minoda et al. 2004) in 200-mL flasks. Flasks were shaken under continuous illumination provided by fluorescent tubes at a fluence rate of $40 \mu \mathrm{mol}$ photons $\mathrm{m}^{-2} \mathrm{~s}^{-1}$ at $40{ }^{\circ} \mathrm{C}$. For measurement of growth rate, $\mathrm{C}$. merolae cells, to which were added $50 \mathrm{mM}$ glycerol, $50 \mathrm{mM}$ succinic acid ( $\mathrm{pH} 4.7$ ), or $5 \mathrm{mM}$ lactic acid ( $\mathrm{pH} 2.5$ ), 
were grown under continuous light provided by LED lighting system at a fluence rate of $8 \mu \mathrm{mol}$ photons $\mathrm{m}^{-2} \mathrm{~s}^{-1}$ with aeration by ordinary air or under continuous light at a fluence rate of $50 \mu \mathrm{mol}$ photons $\mathrm{m}^{-2} \mathrm{~s}^{-1}$ with aeration by air containing $1 \% \mathrm{CO}_{2}$ at $40{ }^{\circ} \mathrm{C}$. Because cells died if $5 \mathrm{mM}$ lactic acid was added to a culture at a time, lactic acid was added stepwise; namely, 0.2, 0.6, 1, 2, and $5 \mathrm{mM}$ lactic acid (final concentrations) were added to the culture at every $2 \mathrm{~min}$. $\mathrm{OD}_{750}$ of cultures was measured over 2 days, and doubling time was calculated.

\section{Culture of $C$. merolae in a flat-plate culture apparatus}

Subcultured cells $(200 \mathrm{~mL})$ were grown to $\mathrm{OD}_{750}=4-5$ with aeration by $1 \% \mathrm{CO}_{2}$ at $40{ }^{\circ} \mathrm{C}$, and centrifuged at $4000 \mathrm{~g}$ for $5 \mathrm{~min}$ at $35{ }^{\circ} \mathrm{C}$. The precipitated cells were resuspended in $50 \mathrm{~mL} 2 \times$ Allen's medium to $\mathrm{OD}_{750}=10$ in a 100 - $\mathrm{mL}$ flask. The concentrated culture in the flask was shaken under continuous light at a fluence rate of $40 \mu \mathrm{mol}$ photons $\mathrm{m}^{-2} \mathrm{~s}^{-1}$ at $40^{\circ} \mathrm{C}$ overnight. The culture was transferred into a flat-plate culture apparatus (Moriyama et al. 2014b), which was assembled from materials for gel electrophoresis consisting of two glass plates with a silicone spacer (clearance of $2 \mathrm{~mm}$ ), equipped with two silicone tubes $(0.8 \mathrm{~mm}$ wall, Bio-Rad Laboratories, Hercules, CA, USA) for aeration. The cells were cultured in the flat-plate culture apparatus under high light provided by two $20 \mathrm{~W}$ krypton bulbs $\left(250 \mu \mathrm{mol}\right.$ photons $\left.\mathrm{m}^{-2} \mathrm{~s}^{-1}\right)$ with aeration by $1 \% \mathrm{CO}_{2}$ at $40{ }^{\circ} \mathrm{C}$.

\section{Construction of GFP-fusion gene}

For the construction of $N$-terminal fusion of EGFP with metabolic enzymes expressed by the APCC promoter, first, the EGFP gene fragment, which was amplified by PCR with pEGFP vector (Clontech Laboratories, Mountain View, CA, USA) as a template with

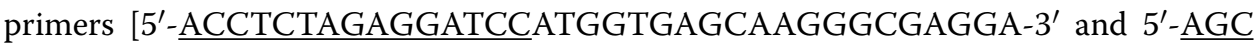
CGGGCGGCCGCTTTACTTGTACAGCTCGTCCA-3'; underlined sequences are required for cloning using the In-Fusion reaction (Clontech Laboratories)], was inserted into DNA fragment containing the APCC promoter and NOS terminator, which was amplified by PCR with pCG1 vector (Watanabe et al. 2011) as a template with primers (5'-GGATCCTCTAGAGGTCAACGAACGAAGAAACACAG-3' and 5'-AGCG GCCGCCCGGCTGCAGATCGTTCAAACATTTG-3') using In-Fusion HD cloning kit (Clontech Laboratories), and the plasmid was named pCEG1 vector. Metabolic genes were amplified by PCR with specific primer sets; for $\mathrm{NAD}^{+}$-dependent glycerol 3-phosphate dehydrogenase (GPD1-1, CMD113C), 5'-TCGTTGACCTCTAGAATGACGGAGAA ACATAAGGT-3' and 5'-CATGGATCCTCTAGACGATTCTGTCTTCGTTTTGA-3'; for GPD1-2 (CMR476C), 5'-TCGTTGACCTCTAGAATGCAGCCTGAGCAAACT GT-3' and 5'-CATGGATCCTCTAGAACCATTGTTAGCCAAGGCAA-3'; for FADdependent glycerol 3-phosphate dehydrogenase (GPD2, CML209C), 5'-TCGTTGA CCTCTAGAATGATGCCCTGCGTTCGTAT-3' ${ }^{\prime}$ and $5^{\prime}$-CATGGATCCTCTAGAGTCG AGTGCAACGCCGGAGC-3'; for glycerol kinase (CMJ173C), 5'-TCGTTGACCTCTA GAATGAAAGAGAAACGCTTTGC-3' and 5' ${ }^{\prime}$-CATGGATCCTCTAGAAATGTCG GCAGGCTTTATGC-3'; for lactate dehydrogenase, 5'-TCGTTGACCTCTAGAATGA CGTCGGGGATCGACGA-3' and 5' ${ }^{\prime}$-CATGGATCCTCTAGATCGGGTCAAAATATT ATAGG-3'. Underlined sequences in primer sequences are required for cloning using 
the In-Fusion reaction. The amplified DNA fragments were inserted into XbaI-cut pCEG1 vector with In-Fusion HD cloning kit. C. merolae encodes five lactate dehydrogenases, which have high sequence similarity with each other, and the cloned lactate dehydrogenase was determined as CMA145C of protein ID by DNA sequencing.

\section{Transformation of $C$. merolae cells and observation of subcellular localization}

Cyanidioschyzon merolae cells were transformed by the PEG-method according to Moriyama et al. (2014b). Observation of EGFP-fusion proteins with immunofluorescence detection using anti-GFP antibody was performed as previously reported (Moriyama et al. 2014a).

\section{RNA purification and quantitative RT-PCR}

Preparation of total RNA and quantitative RT-PCR were performed as described in Moriyama et al. (2010). Briefly, total RNA was prepared by RNeasy Plant Mini kit and RNase-Free DNase Set (Qiagen, Hilden, Germany). First-strand cDNA was prepared using $0.5 \mu \mathrm{g}$ of total RNA and random primers by SuperScript III reverse transcriptase (Invitrogen, Carlsbad, CA, USA) and Recombinant Ribonuclease Inhibitor (Takara, Otsu, Japan). Quantitative PCR was performed using Power SYBR Green PCR Master Mix (Applied Biosystems, Foster City, CA, USA) and appropriate primers in a Real-time PCR system (model 7300, Applied Biosystems). The primers, which were designed by Primer Express software (Applied Biosystems), are listed in Additional file 1: Table S1. The 18S rRNA gene was used to normalize transcript abundance.

\section{Measurement of respiration and photosynthesis}

Rates of respiration and photosynthesis of $C$. merolae culture were measured polarographically at $40{ }^{\circ} \mathrm{C}$ in Oxytherm with an Oxygraph controller (Hansatech Instruments Ltd., Norfolk, UK). Cells were irradiated by high light $(6000 \mu \mathrm{mol}$ photons $\mathrm{m}^{-2} \mathrm{~s}^{-1}$ ) during the measurement of photosynthetic rate. For kinetic analysis, curve fitting was performed with the modified Michaelis-Menten equation: $v=V_{\max } \cdot\left([S]+\left[S_{\text {in }}\right]\right) / K_{\mathrm{s}}+\left([S]+\left[S_{\text {in }}\right]\right)$ by the software SigmaPlot 12.5 (Systat Software, San Jose, CA, USA). $V_{\max }\left(\mathrm{nmol} \mathrm{O}_{2}[\mathrm{mg} \text { protein }]^{-1} \mathrm{~min}^{-1}\right)$ indicates maximal velocity of respiration. $K_{\mathrm{s}}$ indicates the substrate concentration which corresponds to the half of $V_{\max }$. $S$ means the concentration of exogenous substrate. $S_{\text {in }}$ means hypothetical concentration of intracellular substrate.

\section{Measurement of floridean starch and protein contents}

Quantitation of starch was performed using Glycogen Colorimetric Assay kit II (BioVision, Milpitas, CA, USA). For sample preparation, $50 \mu \mathrm{L}$ of $C$. merolae culture grown in a flat-plate culture apparatus was collected by centrifugation at $1200 \mathrm{~g}$ for $5 \mathrm{~min}$, and the precipitated cells were resuspended in $90 \%$ ethanol $(\mathrm{v} / \mathrm{v})$, and centrifuged at $10,000 \mathrm{~g}$ for $2 \mathrm{~min}$. This wash process was repeated twice. The washed cells containing starch were completely lysed with $100 \mu \mathrm{L}$ of $10 \mathrm{~N} \mathrm{KOH}$ at $100{ }^{\circ} \mathrm{C}$ for $5 \mathrm{~min}$ and were neutralized with $26 \mu \mathrm{L}$ of $43.8 \mathrm{~N} \mathrm{H}_{3} \mathrm{PO}_{4}$. The solubilized starch solution was diluted into 20-fold with the Glycogen Hydrolysis Buffer in the (Glycogen Colorimetric Assay) kit. 
Subsequent manipulation was performed according to the protocol of the Glycogen Colorimetric Assay kit II. Protein content was measured by the Lowry method.

\title{
Measurement of cell geometry
}

Cyanidioschyzon merolae cells were observed without fixation under a fluorescence microscope BX-60 (Olympus, Tokyo, Japan). Nomarski differential interference image was recorded by a digital camera (model DP-70, Olympus) and the area and the length of plastid and extra-plastid compartments were measured by ImageJ software (http://rsb. info.nih.gov/ij/).

\section{Additional file}

Additional file 1: Table S1. List of primers for quantitative RT-PCR. All primers were designed by Primer Express software (Applied Biosystems). Slope and amplification efficiency (E) of each primer pair in quantitative-PCR are also shown. Figure S1 Changes in cell size and shape of C. merolae cell in the flat-plate culture. (a) A plot for areas of a plastid and an extraplastid at 0, 1, 3, and $6 \mathrm{~h}$ in the culture. Compartmentation of the plastid and extraplastid is explained in Fig. 1f. Plots for lateral and longitudinal diameters of a plastid (b) and an extraplastid (c). Areas and diameters were measured for 30 cells in each culture time. Figure $\mathbf{S 2}$ Changes in expression level of genes involved in central carbon metabolism in the flat-plate culture. The transcript level of each gene was measured by quantitative RT-PCR, and corrected using transcript levels of $18 \mathrm{~S}$ rRNA gene as an internal standard, and then normalized to the transcript level of each gene at $0 \mathrm{~h}$. Genes are classified into six classes with respect to the peak of transcript level; genes of <2-fold change (a), 2 to 4-fold changes (b), 4 to 8-fold changes (c), 8 to 16-fold changes (d), 16 to 32 -fold changes (e), and $>32$-fold change (f). Each value is an average \pm standard deviation of three independent assays. Figure S3 Culture under the darkness with addition of organic substances. C. merolae was cultured in a flask with rotary-shaking under the dark condition with addition of $200 \mathrm{mM}$ glucose, $200 \mathrm{mM}$ glycerol, $200 \mathrm{mM}$ succinic acid, or $5 \mathrm{mM} \mathrm{L-lactic} \mathrm{acid} \mathrm{for} \mathrm{four} \mathrm{weeks} \mathrm{and} \mathrm{OD}_{750}$ was measured every one week. In the assay, the cells were exposed to room light at the sampling time for a short period of time.

\begin{abstract}
Abbreviations
2OG: 2-oxoglutarate; DHAP: dihydroxyacetone phosphate; G3P: glycerol 3-phosphate; G6P: glucose 6-phosphate; GAP: glyceraldehyde 3-phosphate; GAPC: glyceraldehyde 3-phosphate dehydrogenase; GK: glycerol kinase; GPD: glycerol 3-phosphate dehydrogenase; HA: hemagglutinin; LDH: lactate dehydrogenase; PEG: polyethylene glycol; PEP: phosphoenolpyruvate; PFK: ATP-dependent phosphofructokinase; PFP: PPi-dependent phosphofructokinase; PGAM: phosphoglycerate mutase; PGK: phosphoglycerate kinase; PGL: 6-phosphogluconolactonase; PK: pyruvate kinase; PYR: pyruvate; RPI: ribose-5-phosphate isomerase; TPI: triosephosphate isomerase.
\end{abstract}

Authors' contributions

TM and NS conceived this study. All authors designed and evaluated the experiments. TM mainly and NM partly performed the experiments. TM and NS wrote the manuscript. All authors read and approved the final manuscript.

\section{Author details}

1 Department of Life Sciences, Graduate School of Arts and Sciences, The University of Tokyo, Komaba 3-8-1, Meguro-ku, Tokyo 153-8902, Japan. ${ }^{2}$ JST, CREST, K's Gobancho 7 Gobancho, Chiyoda-ku, Tokyo 102-0076, Japan.

\section{Acknowledgements}

This work was supported in part by Core Research for Evolutional Science and Technology (CREST) from the Japan Science and Technology Agency (JST), Grants-in-Aid for Young Scientists (B) from JSPS (no. 25870155), and the Sasakawa Scientific Research Grant from The Japan Science Society.

\section{Compliance with ethical guidelines}

\section{Competing interests}

The authors declare that they have no competing interests.

Received: 13 May 2015 Accepted: 21 September 2015

Published online: 28 September 2015

\section{References}

Antia NJ, Kalley JP, McDonald J, Bisalputra T (1973) Ultrastructure of the marine cryptomonad Chroomonas salina cultured under conditions of photoautotrophy and glycerol-heterotrophy. J Protozool 20:377-385 
Barbier G, Oesterhelt C, Larson MD, Halgren RG, Wilkerson C, Garavito RM, Benning C, Weber AP (2005) Comparative genomics of two closely related unicellular thermo-acidophilic red algae, Galdieria sulphuraria and Cyanidioschyzon merolae, reveals the molecular basis of the metabolic flexibility of Galdieria sulphuraria and significant differences in carbohydrate metabolism of both algae. Plant Physiol 137:460-474

Droop MR (1974) Heterotrophy of carbon. In: Stewart WDP (ed) Algal physiology and biochemistry. Blackwell Scientific, Oxford, pp 530-559

Fujiwara T, Tashiro K, Yoshida Y, Nishida K, Yagisawa F, Imamura S, Yoshida M, Mori T, Tanaka K, Kuroiwa H, Kuroiwa T (2009) Periodic gene expression patterns during the highly synchronized cell nucleus and organelle division cycles in the unicellular red alga Cyanidioschyzon merolae. DNA Res 16:59-72

Geider R, Osborne BA (1989) Respiration and microalgal growth: a review of the quantitative relationship between dark respiration and growth. New Phytol 112:327-341

Groenewald J-H, Botha FC (2007) Down-regulation of pyrophosphate: fructose 6-phosphate 1-phosphotransferase (PFP) activity in sugarcane enhances sucrose accumulation in immature internodes. Transgenic Res 17:85-92

Gross W, Schnarrenberger C (1995) Heterotrophic growth of two strains of the acido-thermophilic red alga Galdieria sulphuraria. Plant Cell Physiol 36:633-638

Hirabaru C, Izumo A, Fujiwara S, Tadokoro Y, Shimonaga T, Konishi M, Yoshida M, Fujita N, Nakamura Y, Yoshida M, Kuroiwa T, Tsuzuki M (2010) The primitive rhodophyte Cyanidioschyzon merolae contains a semiamylopectin-type, but not an amylose-type, $\alpha$-glucan. Plant Cell Physiol 51:682-693

Hoefnagel MHN, Atkin OK, Wiskich JT (1998) Interdependence between chloroplasts and mitochondria in the light and the dark. Biochim Biophys Acta 1366:235-255

Krömer S (1995) Respiration during photosynthesis. Annu Rev Plant Physiol Plant Mol Biol 46:45-70

Matsuzaki M, Misumi O, Shin-I T, Maruyama S, Takahara M, Miyagishima SY, Mori T, Nishida K, Yagisawa F, Nishida K, Yoshida Y, Nishimura Y, Nakao S, Kobayashi T, Momoyama Y, Higashiyama T, Minoda A, Sano M, Nomoto H, Oishi K, Hayashi H, Ohta F, Nishizaka S, Haga S, Miura S, Morishita T, Kabeya Y, Terasawa K, Suzuki Y, Ishii Y, Asakawa S, Takano H, Ohta N, Kuroiwa H, Tanaka K, Shimizu N, Sugano S, Sato N, Nozaki H, Ogasawara N, Kohara Y, Kuroiwa T (2004) Genome sequence of the ultrasmall unicellular red alga Cyanidioschyzon merolae 10D. Nature 428:653-657

McIntosh CA, Oliver DJ (1992) NAD-linked isocitrate dehydrogenase: isolation, purification, and characterization of the protein from pea mitochondria. Plant Physiol 100:69-75

Minoda A, Sakagami R, Yagisawa F, Kuroiwa T, Tanaka K (2004) Improvement of culture conditions and evidence for nuclear transformation by homologous recombination in a red alga, Cyanidioschyzon merolae 10D. Plant Cell Physiol 45:667-671

Moriyama T, Terasawa K, Sekine K, Toyoshima M, Koike M, Fujiwara M, Sato N (2010) Characterization of cell-cycle-driven and light-driven gene expression in a synchronous culture system in the unicellular rhodophyte Cyanidioschyzon merolae. Microbiology 156:1730-1737

Moriyama T, Sakurai K, Sekine K, Sato N (2014a) Subcellular distribution of central carbohydrate metabolism pathways in the red alga Cyanidioschyzon merolae. Planta 240:585-598

Moriyama T, Tajima N, Sekine K, Sato N (2014b) Localization and phylogenetic analysis of enzymes related to organellar genome replication in the unicellular rhodophyte Cyanidioschyzon merolae. Genome Biol Evol 6:228-237

Nozaki H, Takano H, Misumi O, Terasawa K, Matsuzaki M, Maruyama S, Nishida K, Yagisawa F, Yoshida Y, Fujiwara T, Takio S, Tamura K, Chung SJ, Nakamura S, Kuroiwa H, Tanaka K, Sato N, Kuroiwa T (2007) A 100\%-complete sequence reveals unusually simple genomic features in the hot-spring red alga Cyanidioschyzon merolae. BMC Biol 5:28

Oesterhelt C, Schmälzlin E, Schmitt JM, Lokstein H (2007) Regulation of photosynthesis in the unicellular acidophilic red alga Galdieria sulphuraria. Plant J 51:500-511

Oesterhelt C, Vogelbein S, Shrestha RP, Stanke M, Weber AP (2008) The genome of the thermoacidophilic red microalga Galdieria sulphuraria encodes a small family of secreted class III peroxidases that might be involved in cell wall modification. Planta 227:353-362

Ohnuma M, Yokoyama T, Inouye T, Sekine Y, Tanaka K (2008) Polyethylene glycol (PEG)-mediated transient gene expression in a red alga, Cyanidioschyzon merolae 10D. Plant Cell Physiol 49:117-120

Ohta N, Sato N, Kuroiwa T (1998) Structure and organization of the mitochondrial genome of the unicellular red alga Cyanidioschyzon merolae deduced from the complete nucleotide sequence. Nucleic Acids Res 26:5190-5198

Ohta N, Matsuzaki M, Misumi O, Miyagishima SY, Nozaki H, Tanaka K, Shin-IT, Kohara Y, Kuroiwa T (2003) Complete sequence and analysis of the plastid genome of the unicellular red alga Cyanidioschyzon merolae. DNA Res 10:67-77

Plaxton WC (1996) The organization and regulation of plant glycolysis. Annu Rev Plant Physiol Plant Mol Biol 47:185-214

Radoglou K, Teskey RO (1997) Changes in rates of photosynthesis and respiration during needle development of loblolly pine. Tree Physiol 17:485-488

Rahat M, Jahn TL (1965) Growth of Prymnesium parvum in the dark; note on ichthyotoxin formation. J Protozool $12: 246-250$

Raven J, Johnston A, MacFarlane J (1990) Carbon metabolism. In: Cole KM, Sheath RG (eds) The Biology of the red algae. Cambridge University Press, Cambridge, pp 171-202

Rigano C, Aliotta G, Rigano VD, Fuggi A, Vona V (1977) Heterotrophic growth patterns in the unicellular alga Cyanidium caldarium. A possible role for threonine dehydrase. Arch Microbiol 113:191-196

Shen W, Wei Y, Dauk M, Zheng Z, Zou J (2003) Identification of a mitochondrial glycerol-3-phosphate dehydrogenase from Arabidopsis thaliana: evidence for a mitochondrial glycerol-3-phosphate shuttle in plants. FEBS Lett 536:92-96

Sherson SM, Hemmann G, Wallace G, Forbes S, Germain V, Stadler R, Bechtold N, Sauer N, Smith SM (2000) Monosaccharide/proton symporter AtSTP1 plays a major role in uptake and response of Arabidopsis seeds and seedlings to sugars. Plant J 24:849-857

Tittel J, Bissinger V, Gaedke U, Kamjunke N (2005) Inorganic carbon limitation and mixotrophic growth in Chlamydomonas from an acidic mining lake. Protist 156:63-75

Toda K, Takano H, Miyagishima S, Kuroiwa H, Kuroiwa T (1998) Characterization of a chloroplast isoform of serine acetyltransferase from the thermo-acidiphilic red alga Cyanidioschyzon merolae. Biochim Biophys Acta 1403:72-84 
Truernit E, Stadler R, Baier K, Sauer N (1999) A male gametophyte-specific monosaccharide transporter in Arabidopsis. Plant J 17:191-201

Tsai CH, Warakanont J, Takeuchi T, Sears BB, Moellering ER, Benning C (2014) The protein Compromised Hydrolysis of Triacylglycerols 7 (CHT7) acts as a repressor of cellular quiescence in Chlamydomonas. Proc Natl Acad Sci USA 111:15833-15838

Tyra HM, Linka M, Weber APM, Bhattacharya D (2007) Host origin of plastid solute transporters in the first photosynthetic eukaryotes. Genome Biol 8:R212

Vedel F, Lalanne É, Sabar M, Chétrit P, De Paepe R (1999) The mitochondrial respiratory chain and ATP synthase complexes: composition, structure and mutational studies. Plant Physiol Biochem 37:629-643

Watanabe S, Ohnuma M, Sato J, Yoshikawa H, Tanaka K (2011) Utility of a GFP reporter system in the red alga Cyanidioschyzon merolae. J Gen Appl Microbiol 57:69-72

Zaffagnini M, Fermani S, Costa A, Lemaire SD, Trost P (2013) Plant cytoplasmic GAPDH: redox post-translational modifications and moonlighting properties. Front Plant Sci 4:450

Zenvirth D, Volokita M, Kaplan A (1985) Photosynthesis and inorganic carbon accumulation in the acidophilic alga Cyanidioschyzon merolae. Plant Physiol 77:237-239

\section{Submit your manuscript to a SpringerOpen ${ }^{\circ}$} journal and benefit from:

- Convenient online submission

- Rigorous peer review

- Immediate publication on acceptance

- Open access: articles freely available online

- High visibility within the field

- Retaining the copyright to your article

Submit your next manuscript at $\mathbf{s p r i n g e r o p e n . c o m ~}$ 